\title{
Shape Effect Analysis of the Mechanical Properties of PVC-Coated Fabrics under Off-Axis Tension
}

\author{
Lanlan Zhang $\mathbb{D}^{1,2}$, Yingying Zhang $\mathbb{D}^{1,3}$ Qichong Zhao, ${ }^{1,3}$ Junhao $X u^{1,3}$ and Jigang Xue ${ }^{1,3}$ \\ ${ }^{1}$ Jiangsu Key Laboratory of Environmental Impact and Structural Safety Engineering, China University of Mining \& Technology, \\ Xuzhou 221116, China \\ ${ }^{2}$ School of Construction Management, Jiangsu Vocational Institute of Architectural Technology, Xuzhou 221116, China \\ ${ }^{3}$ Jiangsu Collaborative Innovation Center for Building Energy Saving and Construction Technology, Xuzhou 221116, China \\ Correspondence should be addressed to Yingying Zhang; zhangyingying_cumt@163.com
}

Received 11 February 2020; Revised 24 March 2020; Accepted 20 April 2020; Published 17 June 2020

Academic Editor: Fernando Lusquiños

Copyright (c) 2020 Lanlan Zhang et al. This is an open access article distributed under the Creative Commons Attribution License, which permits unrestricted use, distribution, and reproduction in any medium, provided the original work is properly cited.

\begin{abstract}
This paper selects polyvinyl chloride- (PVC-) coated fabrics to study its off-axial tensile behaviors under different off-axis angles including $0^{\circ}, 15^{\circ}, 30^{\circ}, 45^{\circ}, 60^{\circ}, 75^{\circ}$, and $90^{\circ}$. In the experiment, dumbbell-shaped and strip-shaped specimens are analyzed for shape effect. The variations in the strain distribution are studied by using digital image correlation (DIC) noncontact full-field measurement system. The shape and off-axis angle of specimens are analyzed to predict the influences of shape effect. The results show that the longitudinal strain and shear strain of the coated fabrics are obviously symmetrical to the off-axis direction. The shear strain distribution of the two kinds is basically the same, but the longitudinal strain fields are different. The off-axis tensile properties of the material are obviously anisotropic and nonlinear. The tensile testing curve of the specimens mainly consists of three stages: initial linear stage, deformation strengthening stage, and stress strengthening stage. At $0^{\circ}$, the tensile strength is the largest and the elongation at break is the smallest. In contrast, at $45^{\circ}$, the elongation at break is the highest and the tensile strength was the smallest. The properties under the other off-axis angles were between these two extremes.
\end{abstract}

\section{Introduction}

Coated fabrics are composite materials composed of a highstrength fibers and polymer coating materials, whose mechanical properties have obvious anisotropy $[1,2]$. Due to the curved surface of membrane structure, main direction of material and stress has some deviations after cutting. It has a great effect on the design of membrane structure, which requires stricter engineering determination of membrane materials.

Tensile strength is one of the important mechanical property parameters in the design of a membrane structure. In the current research, various test methods are used to determine the tensile strength of a material. The specimen and loading conditions used in a uniaxial tensile test are relatively simple. Therefore, this test is not only widely used but is also recommended in national standards [3]. At present, most tensile tests are performed along the major axis of the coated fabrics. Although some studies of tensile tests on coated fabrics have been carried out [4-6], which analyzed the tensile properties and fracture mechanism, these existing researches are mainly focused on the mechanical properties of coated fabrics (e.g., tensile strength, elongation at break, and elastic modulus). Moreover, conventional large deformation displacement meters, extensometers, and other devices employed in these studies have limitation in accuracy and applicability, and the full-field strain cannot be obtained exactly. In recent years, digital image correlation (DIC) technique and method has a great improvement [7]. Full-field deformation information of the structure can be recorded during test, which can make it easy to observe the mechanical response of the structure and provide data for studying mechanical properties of the structure and materials $[8,9]$. Yamaguchi $[10]$ and Peters and Ranson [11] first used DIC method in the experiment. After that, the method is gradually adopted to measure the 
surface features of objects and three-dimensional displacement. At present, this method has been widely applied to study the mechanical properties of composite materials for engineering. Many results have shown that DIC technique is more accurate in measuring surface deformation [12-14].

In this study, two shapes of polyvinyl chloride- (PVC-) coated fabrics are selected for off-axis tensile tests, and the noncontact full-field measurement system is adopted to record the specimen; the full-field strain distribution of the membrane material is obtained. The mechanical properties and strain distribution under different off-axis degrees and shapes are analyzed in this paper.

\section{Off-Axis Tensile Test}

2.1. Specimen and Device. In off-axis tensile test, HLD950Acoated fabrics are selected as research object, which have an areal density of $950 \mathrm{~g} / \mathrm{m}^{2}$, a thickness of $0.7 \mathrm{~mm}$, and tensile strength in the warp and weft directions of $88 \mathrm{kN} / \mathrm{m}$ and $84 \mathrm{kN} / \mathrm{m}$, respectively. Based on "Technical Specification for Inspection of Membrane Structures," universal testing machine is applied in the uniaxial tensile test [15]. The deformation and force of the material were recorded by the large deformation displacement meter and high-precision load cell equipped on the testing machine.

The specimens of off-axis tensile test have two different shapes: a dumbbell shape and a strip shape. Specific dimensions of specimens were also selected on the basis of "Technical Specification for Inspection of Membrane Structures" [15]. Specimens of different dimensions were designed in accordance with shape effect analysis, as shown in Figure 1. The off-axial specimens are prepared by cutting the samples with the off-axial angles of $0^{\circ}, 15^{\circ}, 30^{\circ}, 45^{\circ}, 60^{\circ}$, $75^{\circ}$, and $90^{\circ}$ from the weft direction, and the rate of tensile test is under quasistatic $100 \mathrm{~mm} / \mathrm{min}$. The same working condition was repeated 3 times for the specimens. During the test, the relative humidity is maintained at $65 \pm 3 \%$, and the temperature was $23 \pm 2^{\circ} \mathrm{C}$. The force-displacement curve is recorded by the computer connected to the universal testing machine.

A noncontact full-field measurement system (VIC-3D) based on a DIC algorithm is applied in the experiment. Images of different stages are recorded by CCD camera with high-resolution $(3264 \times 2448)$ and Tokina-AT-X F4 Pro DX lens. The DIC techniques perform a series of calculations by comparing the changes in deformation information among a subset of images. Then, the displacement and strain fields of the object surface are obtained. The test requires two or more array image collecting devices to capture the deformation process images of prefabricated speckle coating specimen, and visual information of 3D full-field strain data distribution can be obtained through comparison, calculation, and postprocessing of the supporting software. The corresponding test setup is shown in Figure 2.

\section{Test Results and Analysis}

In this paper, the longitudinal strain and shear strain in the plane of the specimen are mainly analyzed. This is because the upper and lower clamps of the testing machine are kept in the same plane, and the tensile direction is along the vertical direction (longitudinal). By comparing and analyzing the testing machine and the VIC-3D system, the results of the tests are used to investigate the off-axis tensile properties of the coated fabrics.

3.1. Longitudinal Strain. Figure 3 shows dumbbell-shaped specimens' and strip-shaped specimens' longitudinal strain field distributions during the test. The longitudinal strain field is symmetrically distributed in the direction of warp fiber (off-axis direction) being the axis. The strain is concentrated in the middle rectangular area and evenly distributed. Next, different zones of the dumbbell-shaped specimen vary in stress area. Thus, the minimum strain is close to 0 , which occurs at the trapezoidal area near both sides of the clamped end. However, there is a stress concentration phenomenon occurring at the chamfer of the dumbbell-shaped specimen, and a high strain zone appears in this area, especially in the directions of $0^{\circ}$ and $90^{\circ}$ (Figures 3(a) and 3(d)). This is also the reason why most of the specimens are finally broken from the chamfer and the fracture is flat.

During the off-axis tensile testing process, the longitudinal strain in the strip-shaped specimens is evenly distributed throughout the test area. Although both clamped ends are cushioned with burlap, the strain at the two clamped ends is still higher than that in the middle area. The longitudinal strain field is also symmetrically distributed in the off-axis direction, and the longitudinal strain continuously increases as the off-axis angle changes from $0^{\circ}\left(90^{\circ}\right)$ to $45^{\circ}$. The final failure of the specimens at $0^{\circ}$ (warp) and $90^{\circ}$ (weft) mainly occurs in the middle position, and the fracture is flat. However, fractures of other off-axis specimens show a zigzag shape. This phenomenon occurs because the clamp has certain restrictions on the deformation in the width direction at both ends of the specimen, which generates a substantial shear stress at the clamped ends, thereby causing fractures in this location.

In addition, it has been found that some small areas of high strain occur occasionally at the free boundary of the specimen. Microcracks or microvoids are generated in these areas when the specimens are in the free (unloaded) state, and these microcracks or microvoids likely remain in the fabricated specimens.

From the perspective of different off-axis angles, the longitudinal strain field of the specimen changes regularly along with variations in the off-axis angle. With the off-axis angle changing from $0^{\circ}$ to $45^{\circ}$ and from $90^{\circ}$ to $45^{\circ}$, the longitudinal strain gradually increases in the middle rectangular area and gradually decreases at both clamped ends. In addition, the longitudinal strain field shows a band-like distribution with respect to changes in the off-axis angle. The reason for this phenomenon is that the warp and weft fibers in the clamped region are mainly subjected to large tensile forces when the specimen is subjected to off-axis tension. The warp and weft fibers that do not extend throughout the entire length of the specimen (only one end of the fiber is 


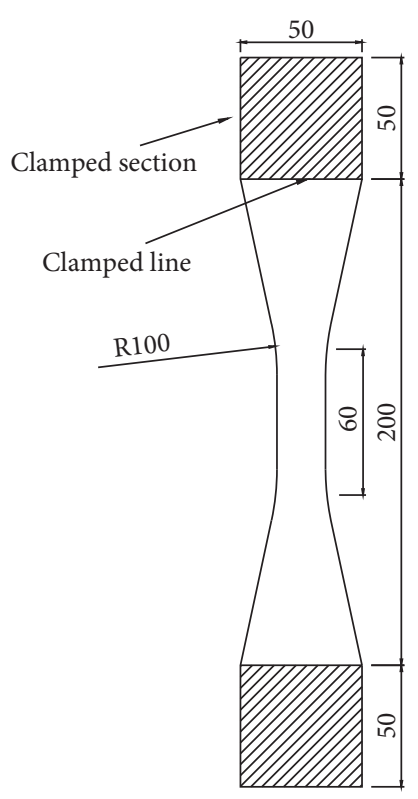

(a)

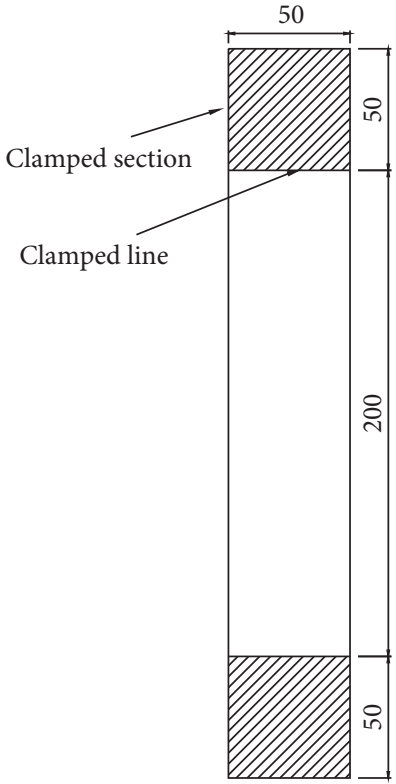

(b)

FIgURE 1: Dimensions of the PVC-coated fabric specimens (units: mm). (a) Dumbbell shape. (b) Strip shape.

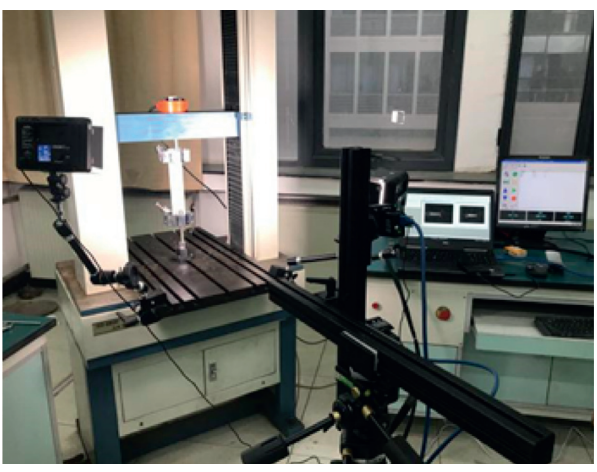

Figure 2: Test setup.

clamped or both ends of the fiber are not clamped) are subjected to lower tensile forces and a less pronounced shearing effect at the coating interface. As the off-axis angle approaches $45^{\circ}$, the number of fibers that extend between both clamped ends and the tensile force on the fiber is gradually reduced. Thus, the longitudinal strain gradually decreases. The fibers passing through the specimen are inconsistent with the direction of the tensile force, which leads to the longitudinal strain field presenting a band-like distribution related to the offaxis direction.

The experiment avoids large accidental errors in the measurement results of a single pixel and comprehensively compares and analyzes the strain distribution in different areas of the specimen. By selecting dumbbell-shaped specimen and the strip-shaped specimen, the experiment analyzes the average value of the longitudinal strain of all pixels in the entire test area (A0) and analyzes the average value of the strain of all pixels in a square area picked at the center of the specimen (R0). As shown in Figure 4, the area surrounded by red lines represents $\mathrm{A} 0$, whereas the area surrounded by blue lines represents R0.

Figure 5 shows the curves of variance with time in the longitudinal strain of the dumbbell-shaped specimens. These data were measured by the VIC-3D system and the universal testing machine. As shown in the figure, the longitudinal strain of the specimen basically increases linearly with respect to time, especially in the strain values measured by the testing machine. This phenomenon occurs because the test is performed at a constant displacement rate. For dumbbellshaped specimens, the average longitudinal strain in R0 is larger than that in $\mathrm{A} 0$, and the gap increases over time. This behavior occurs because the middle zone of the dumbbellshaped specimen has a minimum width, and the middle zone suffers the maximal stress under the same tensile force. In contrast, the two clamped ends are subjected to less stress. Thus, on average, the longitudinal strain in $\mathrm{A} 0$ is less than that in R0. Compared with the longitudinal strain measured by the testing machine, the longitudinal strain in R0 measured by $3 \mathrm{D}-\mathrm{DIC}$ is larger.

For the strip-shaped specimens, the longitudinal strain field of the specimen is distributed more evenly in the entire test area, so the longitudinal strain in $\mathrm{R} 0$ and $\mathrm{A} 0$ measured by $3 \mathrm{D}$-DIC is basically the same, and the gap between the longitudinal strains measured by the testing machine is much smaller than that of the dumbbell-shaped specimens.

The following variable definitions apply to Table 1: $\varepsilon_{y y}^{\mathrm{ME}}$ represents the longitudinal ultimate strain measured by the testing machine; $\varepsilon_{y y}^{\mathrm{A} 0}$ and $\varepsilon_{y y}^{\mathrm{R} 0}$ represent the longitudinal limit strains in $\mathrm{A} 0$ and R0, respectively, measured by VIC-3D; and $\delta_{1}$ and $\delta_{2}$ represent the relative deviation between the longitudinal limit strains in A0 and $\mathrm{R} 0$ and the longitudinal limit strain measured by the testing machine, for which the 


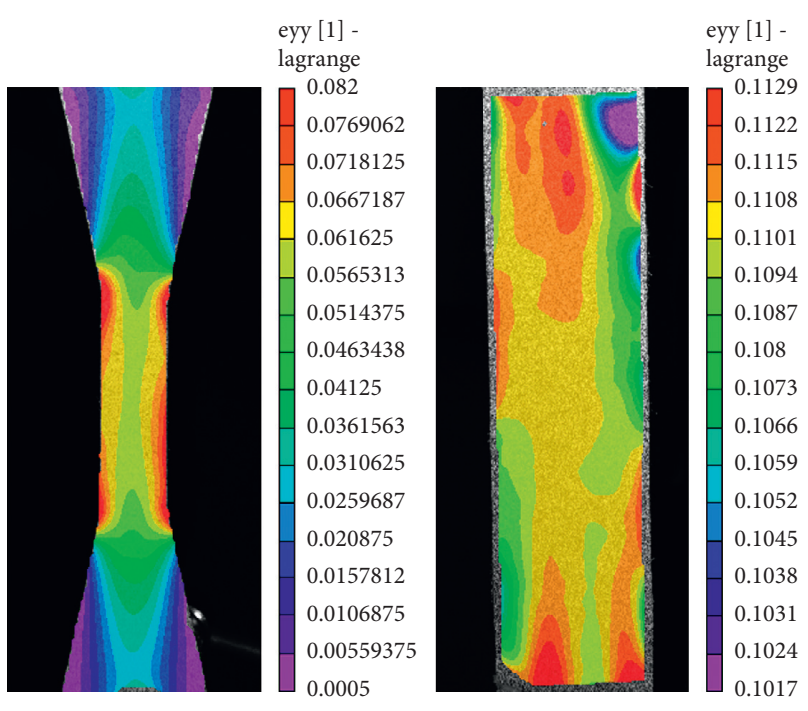

(a)

eyy [1] -

lagrange
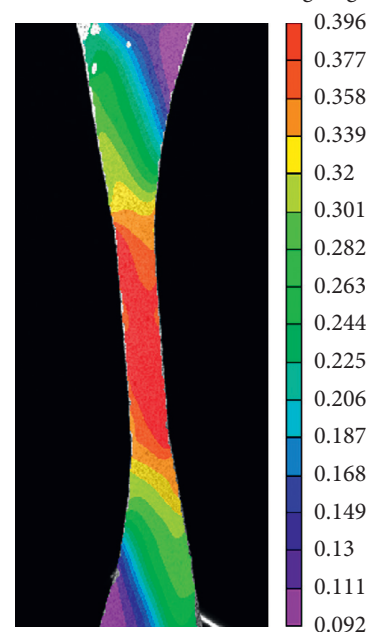

eyy [1] -

lagrange
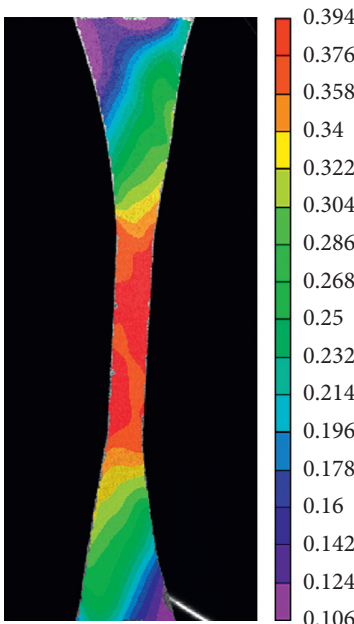

eyy [1] -

lagrange

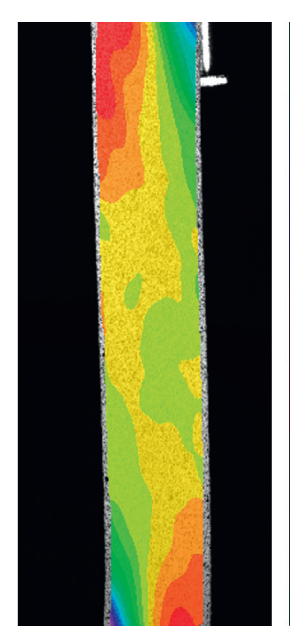

(c)

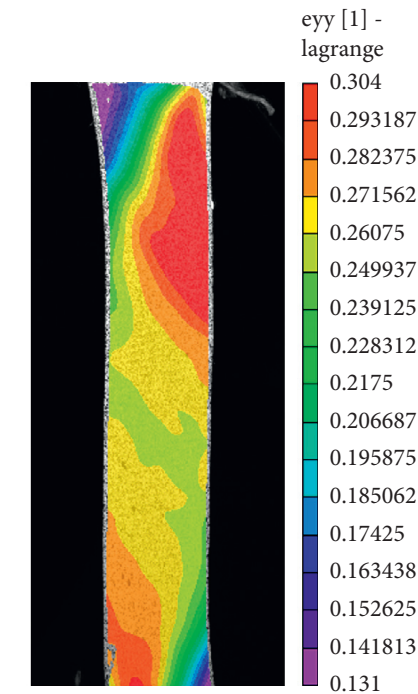

(e)

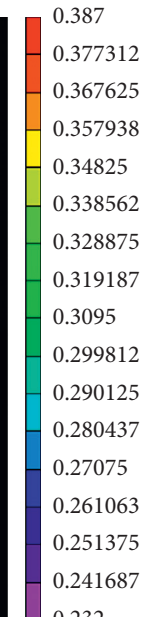

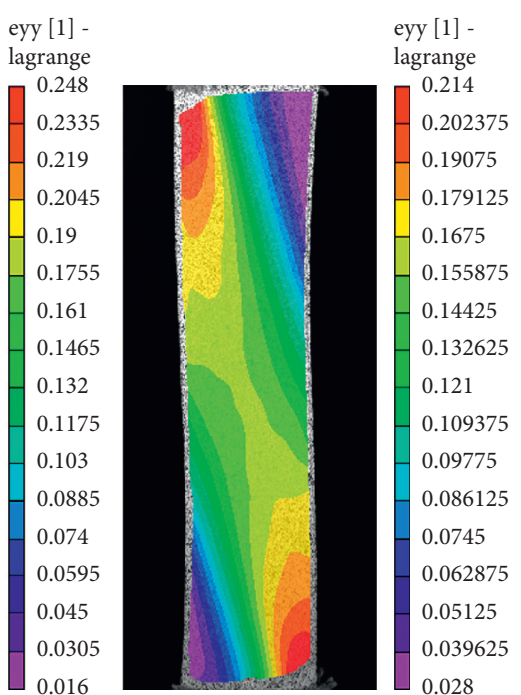

(b)

eyy [1] -

lagrange

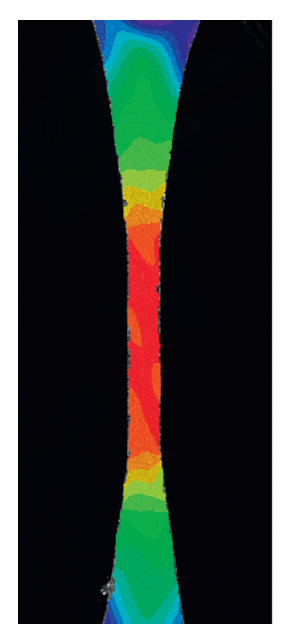

\begin{tabular}{|l}
0.456 \\
0.4355 \\
0.415 \\
0.3945 \\
0.374 \\
0.3535 \\
0.333 \\
0.3125 \\
0.292 \\
0.2715 \\
0.251 \\
0.2305 \\
0.21 \\
0.1895 \\
0.169 \\
0.1485 \\
0.128
\end{tabular}

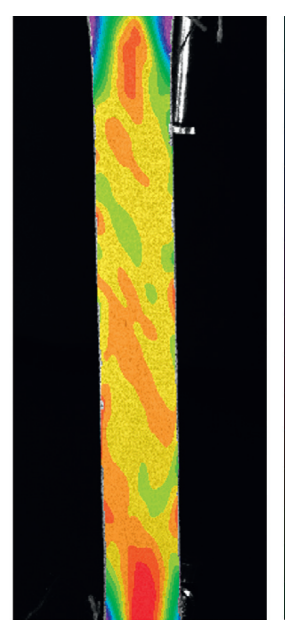

eyy [1] -

agrange

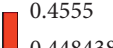

0.448438

0.434313

$-0.42725$

0.420188

0.413125

0.406063

0.399

0.391937

0.384875

0.377813

0.37075

0.363688

0.356625

0.349562

(d)

eyy [1] -

lagrange

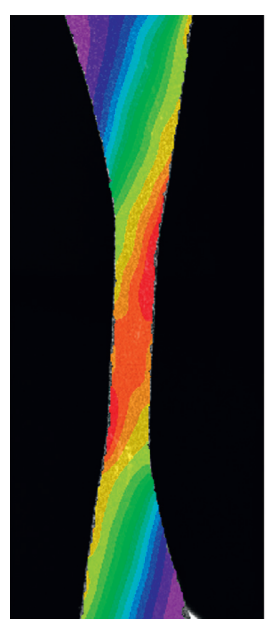

\begin{tabular}{|l}
0.33 \\
0.312 \\
0.294 \\
0.276 \\
0.258 \\
0.24 \\
0.222 \\
0.204 \\
0.186 \\
0.168 \\
0.15 \\
0.132 \\
0.114 \\
0.096 \\
0.078 \\
0.06 \\
0.042
\end{tabular}

eyy [1] -

lagrange

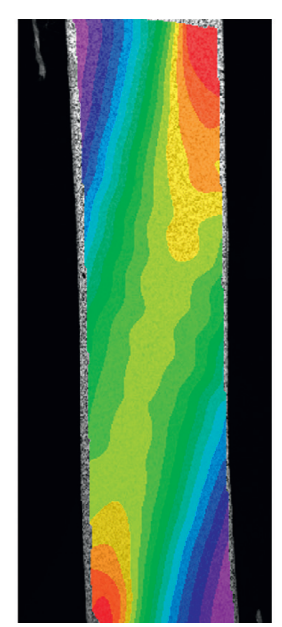

0.1345

0.12775

0.121

0.11425

$-0.1075$

$-0.10075$

0.094

0.08725

0.0805

0.07375

0.067

0.06025

0.0535

0.04675

0.04

0.03325

(f)

Figure 3: Continued. 


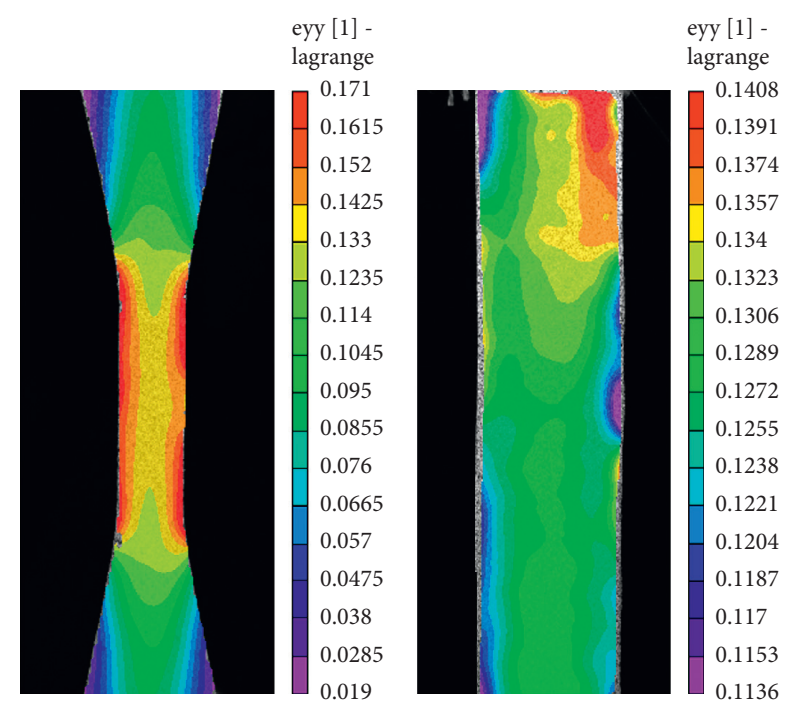

(g)

Figure 3: Longitudinal strain field during tensile testing. (a) $0^{\circ}$. (b) $15^{\circ}$. (c) $30^{\circ}$. (d) $45^{\circ}$. (e) $60^{\circ}$. (f) $75^{\circ}$. (g) $90^{\circ}$.

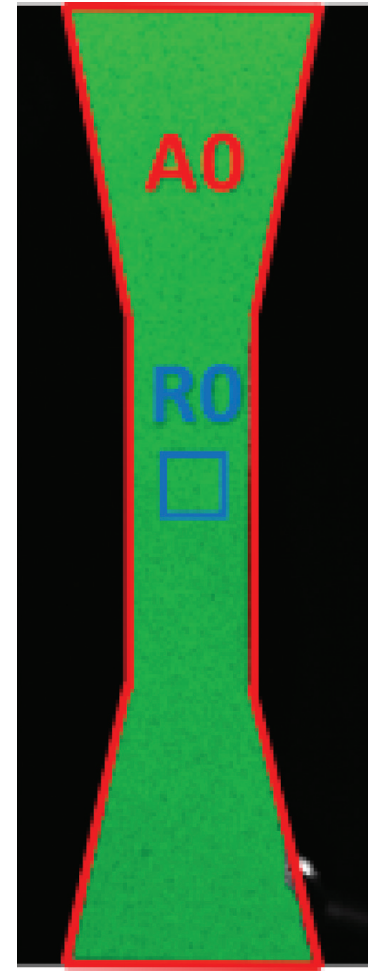

(a)

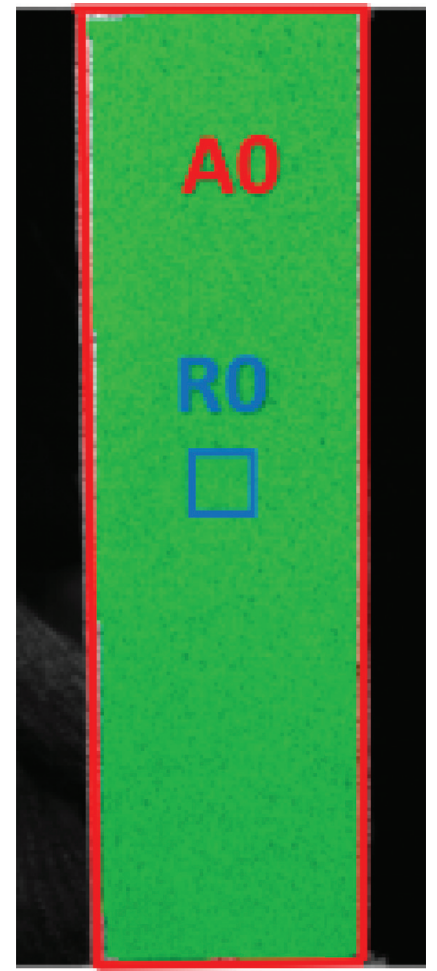

(b)

Figure 4: Data extraction area. (a) Dumbbell shape. (b) Strip shape.

calculation expressions are $\delta_{1}=100 \times\left(\left(\varepsilon_{y y}^{\mathrm{A} 0}-\varepsilon_{y y}^{\mathrm{ME}}\right) / \varepsilon_{y y}^{\mathrm{ME}}\right)$ and $\delta_{2}=100 \times\left(\left(\varepsilon_{y y}^{\mathrm{RO}}-\varepsilon_{y y}^{\mathrm{ME}}\right) / \varepsilon_{y y}^{\mathrm{ME}}\right)$.

Based on the analysis above, it can be concluded that during the off-axis tensile testing process, the longitudinal strain is not evenly distributed on the surface of the specimen. Depending on the location of the selected test area, the longitudinal strain calculated by the VIC-3D system is different; hence, the longitudinal strain and the position of each pixel have a certain relationship. Therefore, to further study the longitudinal strain distribution rule on the surface of the specimen, a vertical line going from top to bottom along the longitudinal axis of the specimen is drawn in the 


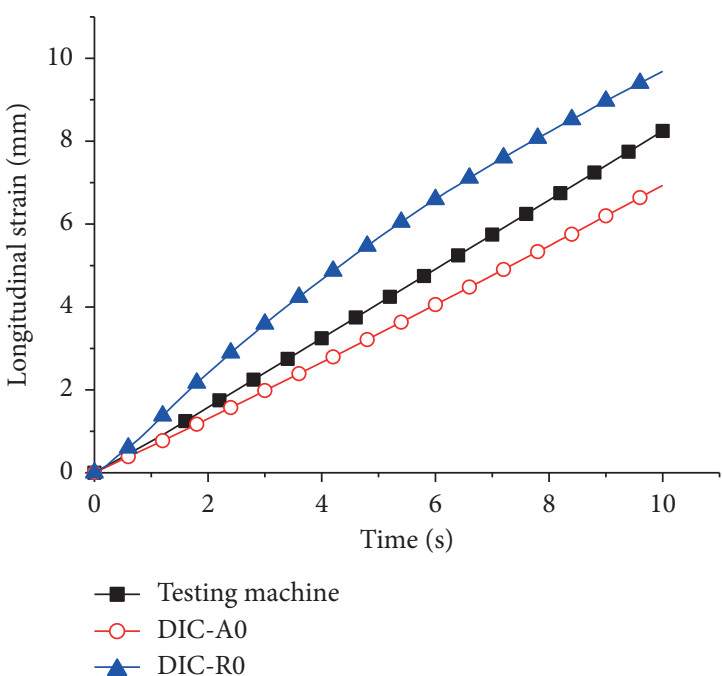

(a)

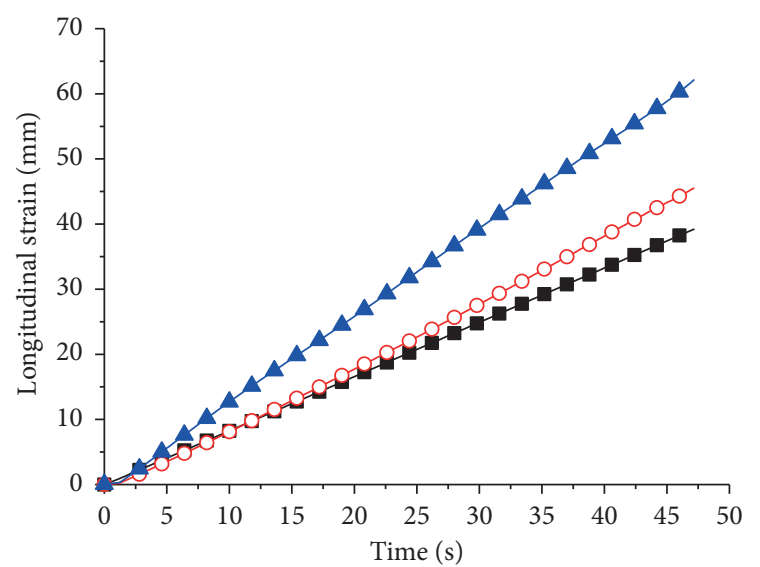

$\rightarrow$ - Testing machine

- - DIC-A0

$\neg$ - DIC-R0

(c)

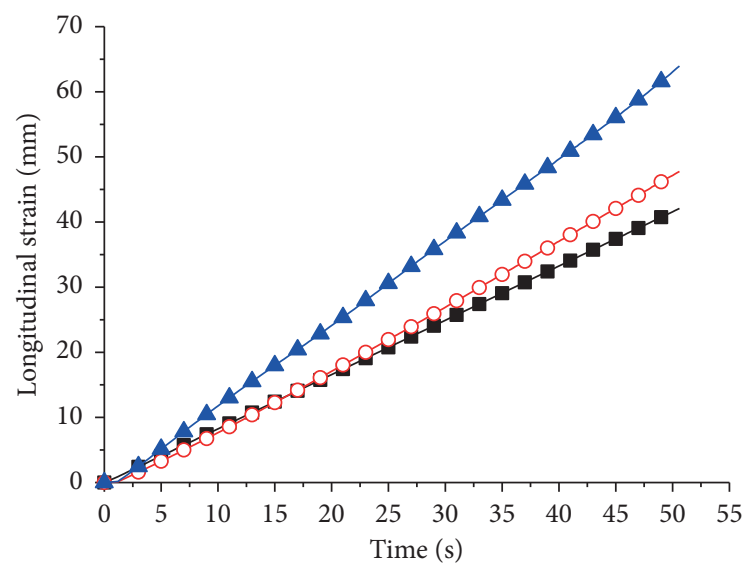

- Testing machine

-O- DIC-A0

$\neg$ DIC-R0

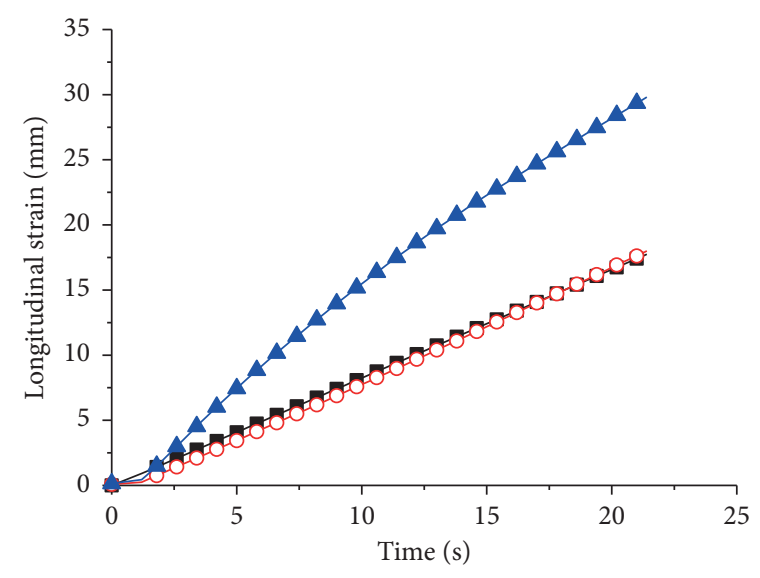

$\rightarrow$ Testing machine

-O- DIC-A0

$\leftarrow$ DIC-R0

(b)

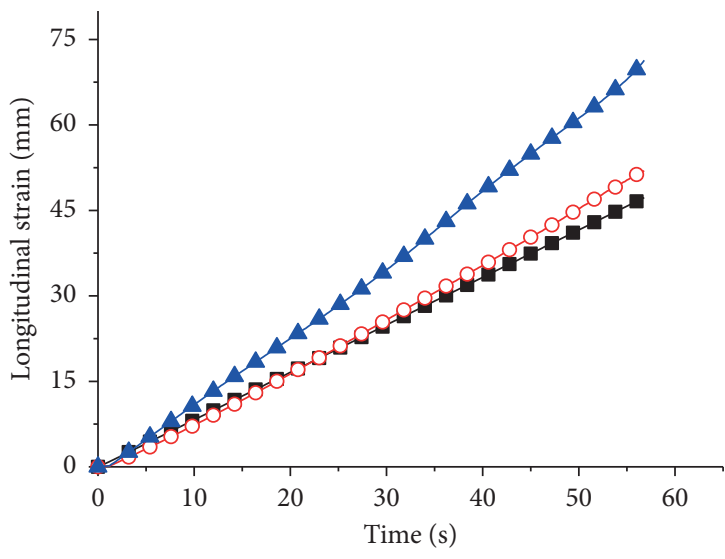

- Testing machine

-O- DIC-A0

$\leftarrow$ DIC-R0

(d)

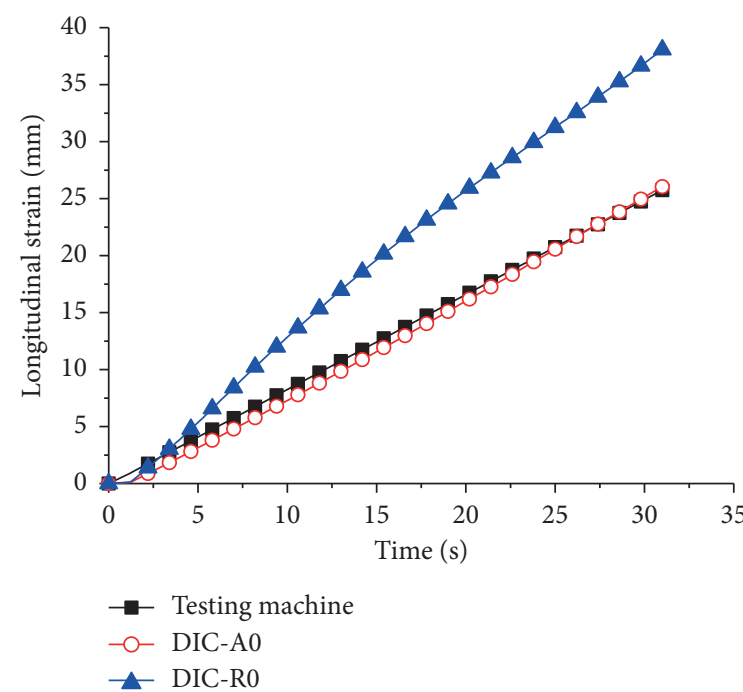

(e)

FIgUre 5: Continued. 


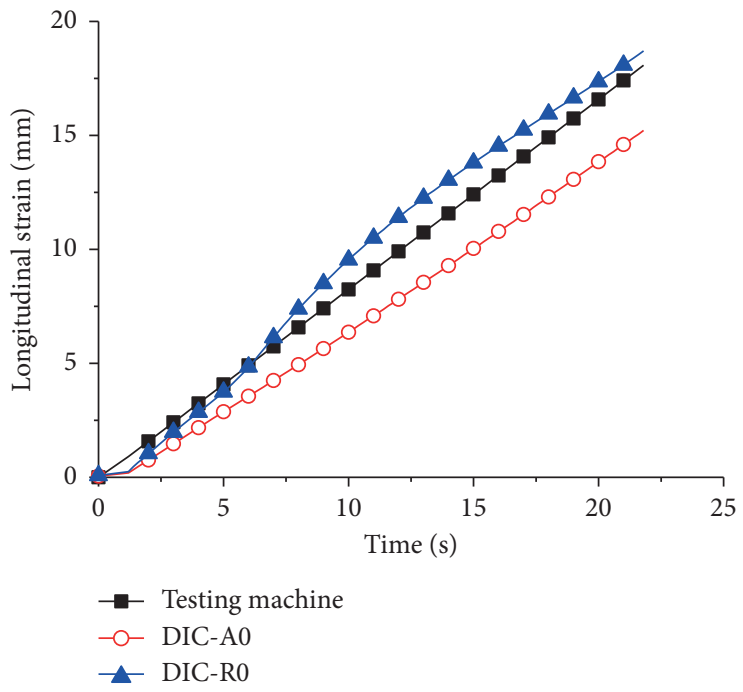

(g)

Figure 5: Longitudinal strains measured by the 3D-DIC system and a mechanical extensometer. (a) $0^{\circ}$. (b) $15^{\circ}$. (c) $30^{\circ}$. (d) $45^{\circ}$. (e) $60^{\circ}$. (f) $75^{\circ}$. (g) $90^{\circ}$.

TABLE 1: Longitudinal ultimate strain of the coated fabrics.

\begin{tabular}{lcccccc}
\hline \multirow{2}{*}{$\begin{array}{l}\text { Off-axis } \\
\text { angle }\end{array}$} & $\begin{array}{c}\text { Specimen } \\
\text { shape }\end{array}$ & \multicolumn{3}{c}{ Longitudinal } & \multicolumn{2}{c}{ Relative } \\
& & $\varepsilon_{y y}^{\mathrm{ME}}$ & $\varepsilon_{y y}^{\mathrm{A} 0}$ & $\varepsilon_{y y}^{\mathrm{R} 0}$ & $\delta_{1}$ & $\delta_{2}$ \\
\hline $0^{\circ}$ & Dumbbell & 9.41 & 7.08 & 9.90 & -24.76 & 5.21 \\
& Strip & 18.58 & 16.31 & 16.38 & -12.22 & -11.84 \\
$15^{\circ}$ & Dumbbell & 17.74 & 18.00 & 29.80 & 1.47 & 67.98 \\
& Strip & 23.41 & 23.30 & 26.13 & -0.47 & 11.62 \\
$30^{\circ}$ & Dumbbell & 39.24 & 45.54 & 62.20 & 16.06 & 58.51 \\
& Strip & 47.24 & 49.26 & 50.03 & 4.28 & 5.91 \\
$45^{\circ}$ & Dumbbell & 47.24 & 51.92 & 71.32 & 9.91 & 50.97 \\
& Strip & 61.74 & 65.12 & 66.06 & 5.47 & 7.00 \\
$60^{\circ}$ & Dumbbell & 42.07 & 47.76 & 63.95 & 13.53 & 52.01 \\
& Strip & 43.24 & 43.82 & 43.30 & 1.34 & 0.14 \\
$75^{\circ}$ & Dumbbell & 25.74 & 26.04 & 38.07 & 1.17 & 47.90 \\
& Strip & 20.57 & 18.42 & 20.70 & -10.45 & 0.63 \\
$90^{\circ}$ & Dumbbell & 18.07 & 15.21 & 18.70 & -15.83 & 3.49 \\
& Strip & 23.57 & 19.90 & 20.17 & -15.57 & -14.43 \\
\hline
\end{tabular}

test area of the VIC-3D system. The initial gauge of the specimen is $200 \mathrm{~mm}$, so 200 pixels on the longitudinal axis are taken. In default, the top endpoint is labeled as 0 , whereas the bottom endpoint is labeled as 199. Then, Figure 6 is drawn to reflect the relationship between the longitudinal ultimate strain (the longitudinal strain before the specimen is broken) and the position of pixels.

Figure 6 shows that the longitudinal ultimate strain is symmetrically distributed on the side of the 99th pixel (horizontal axis of the specimen). For the dumbbell-shaped specimens, when the pixels change from the clamped ends to the middle zone, the longitudinal strain gradually increases, and the strain in the middle strip zone is basically the same. This response occurs because the cross-sectional area of the specimen gradually decreases from the two clamped ends to the middle zone, and the stress on its section gradually increases. As the angle of deviation from the warp and weft increases, the strain gap between the two clamped ends and the middle area increases, which can be observed in Figure 3 . For the strip-shaped specimens, the gap in longitudinal ultimate strain on the entire central axis is close, which further illustrates that the longitudinal strain is distributed more evenly in the strip-shaped specimens than in the dumbbell-shaped specimens. In addition, it is clear that both the dumbbell-shaped specimens and the strip-shaped specimens have the minimal longitudinal ultimate strain at $0^{\circ}$, the maximal value at $45^{\circ}$, and the median value at $90^{\circ}$. As the angle changes from $0^{\circ}$ to $45^{\circ}$ and then to $90^{\circ}$, the longitudinal ultimate strain increases and then decreases, which is mainly determined by the braided structure of the coated fabrics.

3.2. Shear Strain. For the dumbbell-shaped specimens and the strip-shaped specimens, Figure 7 shows the distribution and change in their shear strain field during the off-axis tensile testing process. The shear strain field of the specimen is also symmetrically distributed in the off-axis direction. The shear strain field of the dumbbell-shaped specimens with the middle zone is basically the same as that of the stripshaped specimens. As the tensile force increases, the shear strain increases. The dumbbell-shaped specimens have a larger shear strain in the middle zone, whereas strip-shaped specimens have a more uniform shear strain distribution except for at the two clamped ends. By changing the off-axis angles and comparing the corresponding shear strain fields of the specimens, it is found that during the entire testing process, the specimens have a small shear strain at $0^{\circ}$ and $90^{\circ}$, in which the shear strain is approximately 0 . At $45^{\circ}$, the shear strain increases faster and can reach a maximum value under 


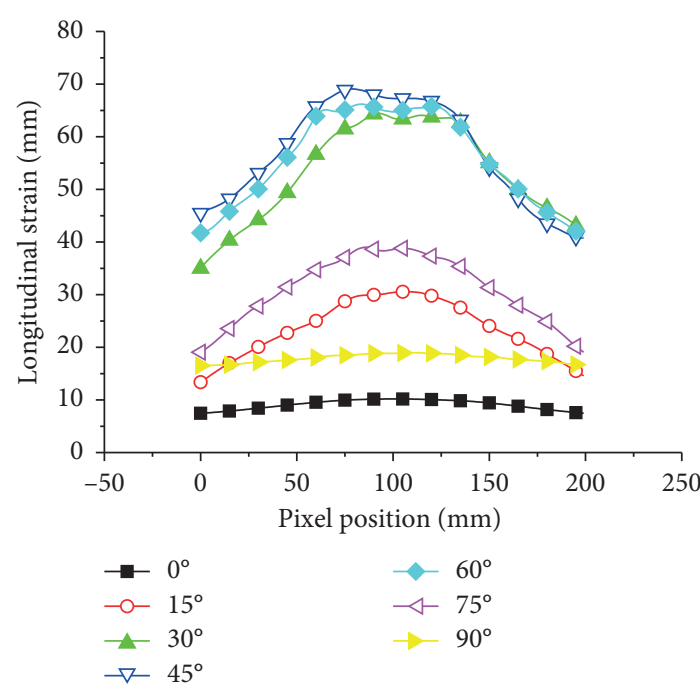

(a)

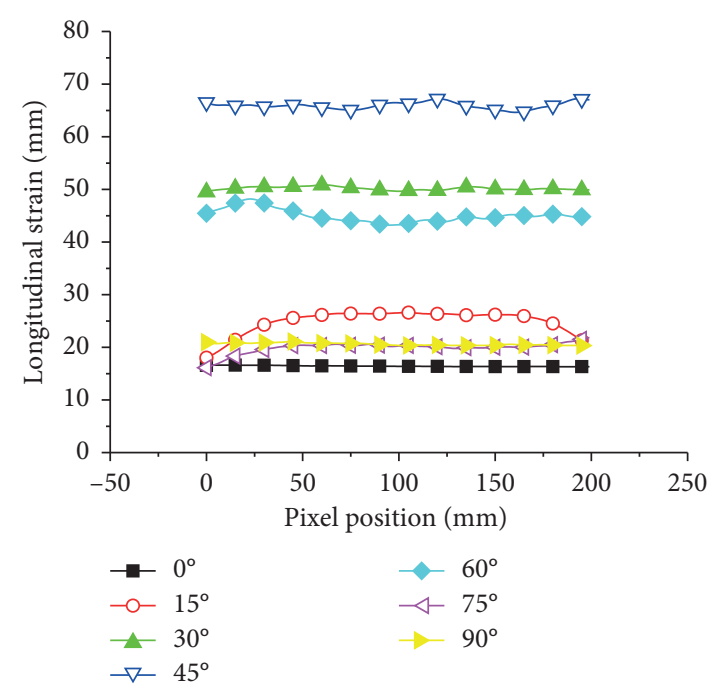

(b)

Figure 6: Relationship between the longitudinal ultimate strain and the pixel position. (a) Dumbbell shape. (b) Strip shape.

the same tensile force, whereas the values in the other directions are between these two extremes.

To more clearly analyze the relationship between the shear strain of the coated fabrics and the off-axis angle, the maximum shear strain of each off-axis angle is selected and drawn in Figure 8. The maximum shear strain changes symmetrically, with $45^{\circ}$ being the axis. The maximum shear strain at $0^{\circ}$ (warp) and $90^{\circ}$ (weft) is approximately 0 when the material is tested at $0^{\circ}$ and $90^{\circ}$, wherein the directions of the warp and weft are consistent with the tensile load direction. Under this condition, the coated fabrics are mainly subjected to normal stress and suffer a small amount of shear stress; thus, the main deformation is fiber elongation. When changing from $15^{\circ}\left(75^{\circ}\right)$ to $45^{\circ}$, the maximum shear strain in the coated fabrics gradually increases. This phenomenon occurs because there exists a certain angle between the direction of the tensile load and that of the warp fibers during the off-axis tensile testing process. The warp fibers deflect from the initial position to the longitudinal direction (tensile direction), which widens the angle between the warp fibers and the weft fibers; thus, the shear strain is negative. In addition, the coating interface of the material also has a certain shear effect on the fiber, which eventually results in a large shear strain. In addition, it is found that the deviation from the warp direction $\left(0^{\circ}, 15^{\circ}\right.$, and $\left.30^{\circ}\right)$ can result in a larger maximum shear strain that corresponds to the deviation from the weft direction $\left(90^{\circ}, 75^{\circ}\right.$, and $\left.60^{\circ}\right)$. This behavior is related to the fiber weaving process of the base fabric, wherein the warp fibers are straight and the weft fibers are slightly bent. When the off-axis angle is greater than $45^{\circ}$, the weft fibers mainly extend throughout the specimen. During the off-axis tensile testing process, deflection occurs only when the weft fibers are fully straightened. Thus, deviations from the warp direction result in larger maximum shear strains than deviations from the weft direction.

When the dumbbell-shaped specimens and the strip specimens are in $\mathrm{A} 0$ and $\mathrm{R} 0$, the results of the maximum shear strains are shown in Table 2. The maximum shear strain at $45^{\circ}$ is approximately 40 times that in the warp and weft directions. There exists a certain deviation in the maximum shear strain in the two zones, especially for the dumbbell-shaped specimens. This phenomenon occurs because the number of fibers extending through the specimen gradually decreases as the angle from the warp and weft directions increases, and there are more fibers that extend through the specimen in the central zone (R0) than in the two clamped ends. In addition, these extended fibers are fixed at the two clamped ends, so they undergo a large deflection during the off-axis tensile testing process. The fibers that do not extend throughout the specimen are subjected to a lower tensile force and a less pronounced shear effect of the coating, which are mainly extracted from the base fabric, so the maximum shear strain in R0 is larger than that in A0.

In the table, $\gamma_{12}^{\mathrm{A} 0}$ and $\gamma_{12}^{\mathrm{R} 0}$ indicate the maximum shear strains in the A0 and R0 areas, respectively, measured by the VIC-3D system in the main direction coordinate system of the material, whereas $\delta$ represents the relative deviation between the maximum shear strain in the A0 region and the maximum shear strain in the $\mathrm{R} 0$ region, for which the expression is $\delta=100 \times\left(\left(\gamma_{12}^{\mathrm{R} 0}-\gamma_{12}^{\mathrm{A} 0}\right) / \gamma_{12}^{\mathrm{A} 0}\right)$.

3.3. Off-Axis Tensile Testing Curve. Figure 9 shows that the stress-strain curve obtained from the 3D-DIC system is basically consistent with the test curve. In the range of stress below $16 \mathrm{kN} / \mathrm{m}$, the $3 \mathrm{D}$-DIC curve basically coincides with the test curve. With increasing stress, the 3D-DIC curve gradually deviates from the test curve. This deviation occurs because the increasing deviation from the warp and weft causes a decrease in the number of fibers passing through the specimen. During tensile testing, as the deviation from the warp and latitudinal angle increases, the gap between the $3 \mathrm{D}$-DIC curve and the test curve also gradually increases. In 

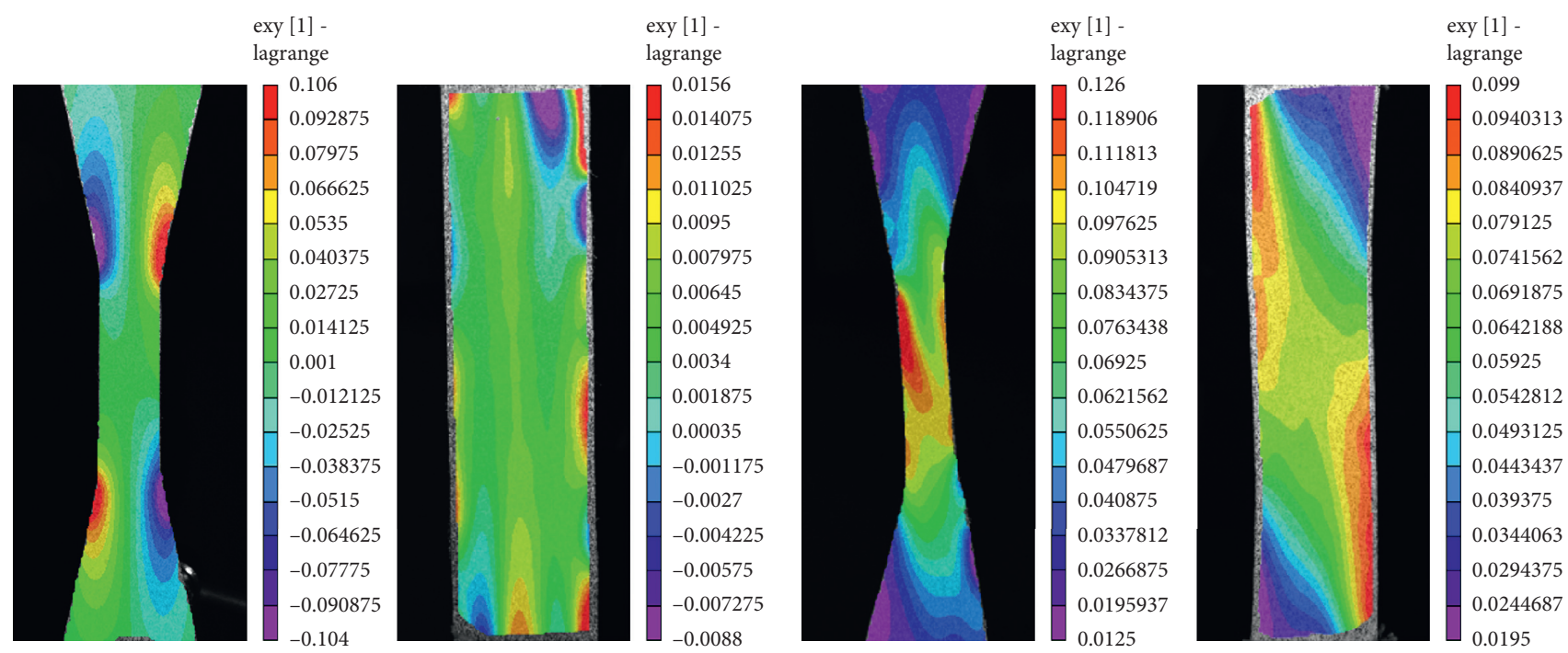

(a)

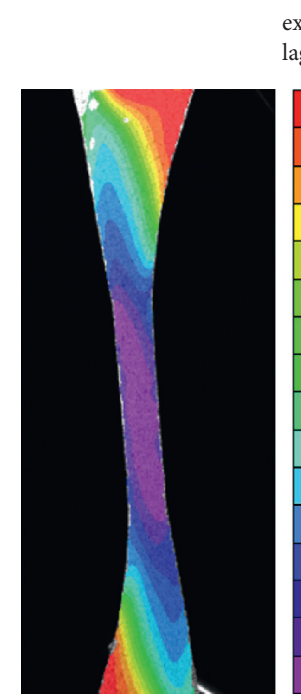

exy [1] -

grange

exy [1] -

lagrange
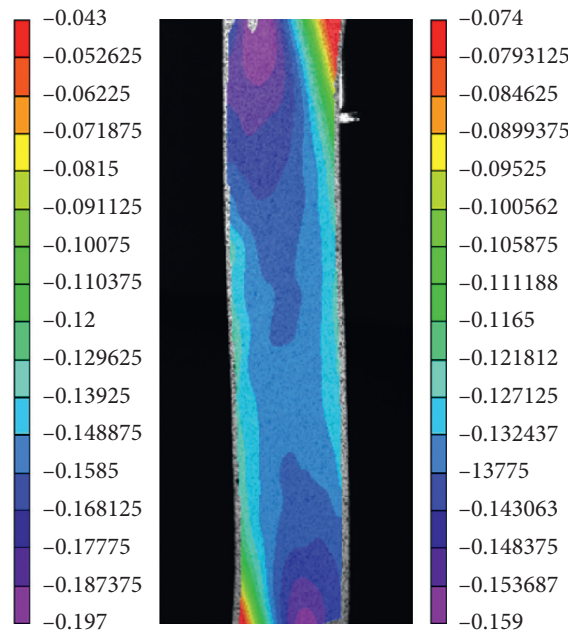

(c)

exy [1] -

lagrange

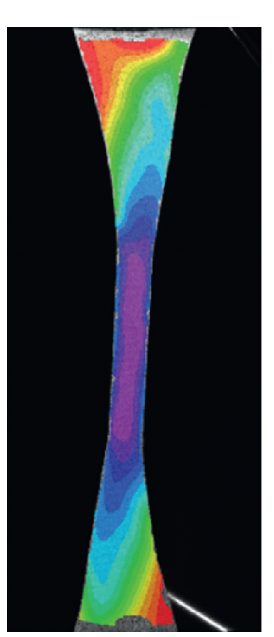

$-0.063$

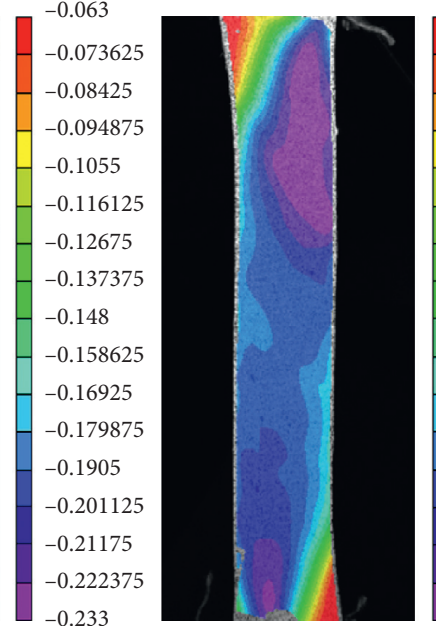

(e) exy [1] -

lagrange

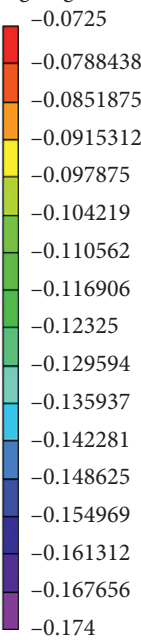

$-0.174$ exy [1] -

lagrange
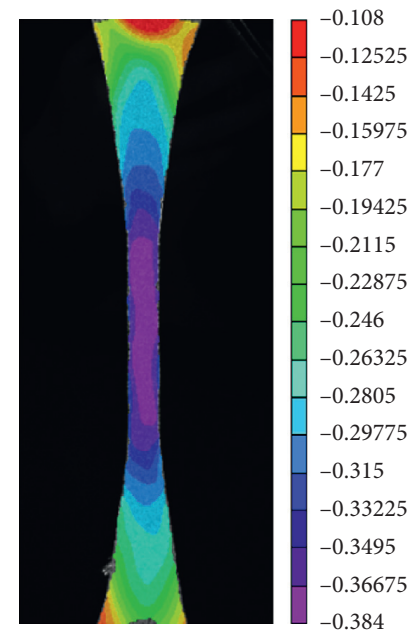

$-0.384$

(d)

exy [1] -

lagrange

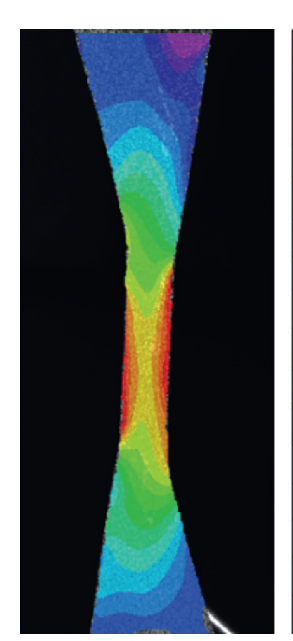

0.1

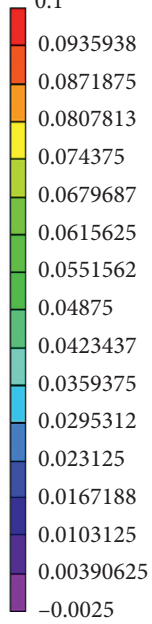

(b)
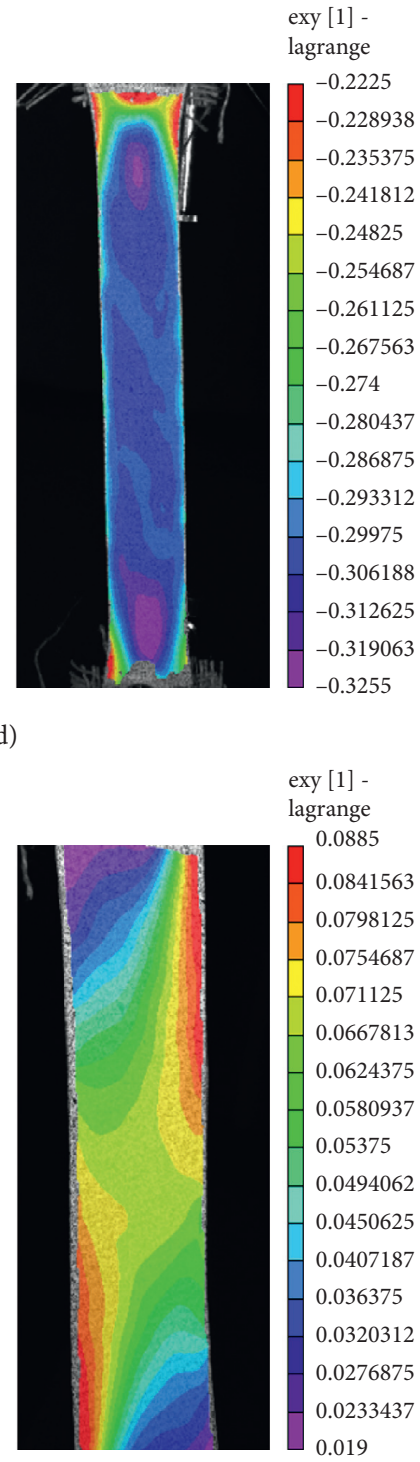

(f)

FIgURe 7: Continued. 


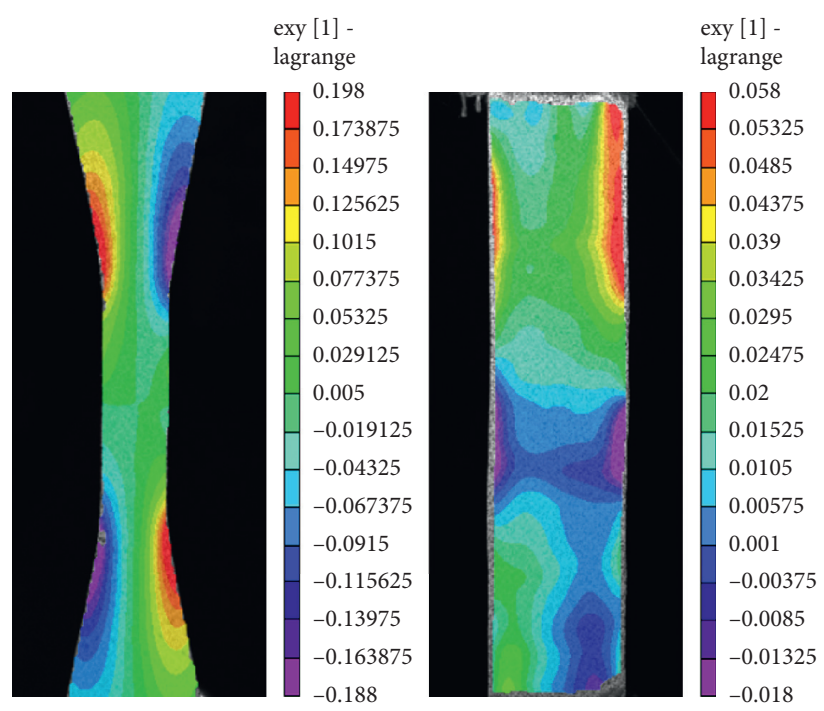

(g)

Figure 7: Shear strain field during tensile testing. (a) $0^{\circ}$. (b) $15^{\circ}$. (c) $30^{\circ}$. (d) $45^{\circ}$. (e) $60^{\circ}$. (f) $75^{\circ}$. (g) $90^{\circ}$.

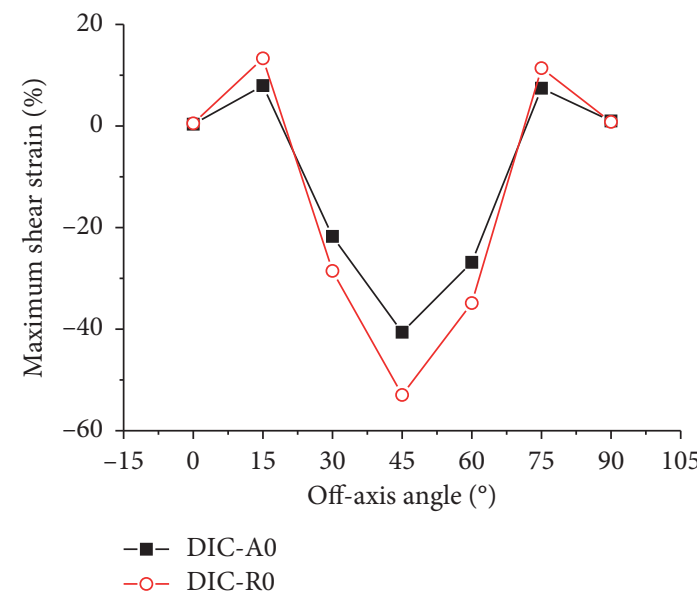

(a)

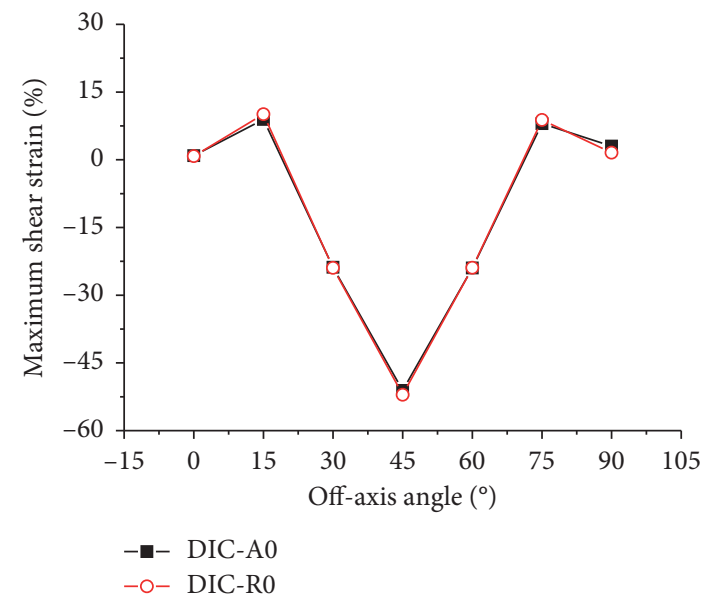

(b)

Figure 8: Variation in maximum shear strain with respect to the off-axis angle. (a) Dumbbell shape. (b) Strip shape.

TABLE 2: Results of the maximum shear strain.

\begin{tabular}{|c|c|c|c|c|}
\hline \multirow{2}{*}{ Off-axis angle } & \multirow{2}{*}{ Specimen shape } & \multicolumn{2}{|c|}{ Maximum shear strain (\%) } & \multirow{2}{*}{$\begin{array}{c}\text { Relative deviation (\%) } \\
\delta\end{array}$} \\
\hline & & $\gamma_{12}^{\mathrm{A} 0}$ & $\gamma_{12}^{\mathrm{R} 0}$ & \\
\hline \multirow{2}{*}{$0^{\circ}$} & Dumbbell & 0.34 & 0.53 & 53.77 \\
\hline & Strip & 0.90 & 0.82 & -9.42 \\
\hline \multirow{2}{*}{$15^{\circ}$} & Dumbbell & 7.95 & 13.31 & 67.31 \\
\hline & Strip & 8.92 & 10.10 & 13.12 \\
\hline \multirow{2}{*}{$30^{\circ}$} & Dumbbell & -21.75 & -28.55 & 31.29 \\
\hline & Strip & -23.80 & -23.94 & 0.58 \\
\hline \multirow{2}{*}{$45^{\circ}$} & Dumbbell & -40.61 & -52.96 & 30.42 \\
\hline & Strip & -51.11 & -52.05 & 1.83 \\
\hline \multirow{2}{*}{$60^{\circ}$} & Dumbbell & -26.85 & -34.87 & 29.85 \\
\hline & Strip & -23.97 & -23.92 & -0.22 \\
\hline \multirow{2}{*}{$75^{\circ}$} & Dumbbell & 7.43 & 11.40 & 53.37 \\
\hline & Strip & 8.02 & 8.81 & 9.96 \\
\hline \multirow{2}{*}{$90^{\circ}$} & Dumbbell & 0.98 & 0.80 & -18.05 \\
\hline & Strip & 3.02 & 1.56 & -48.46 \\
\hline
\end{tabular}




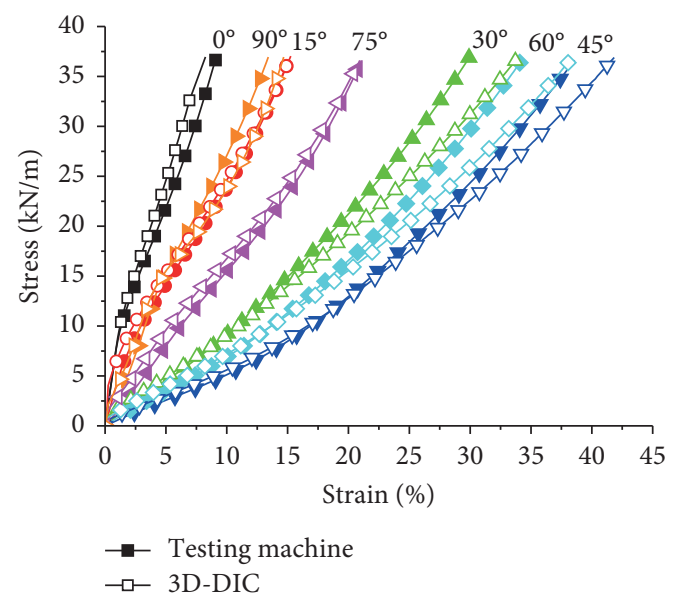

(a)

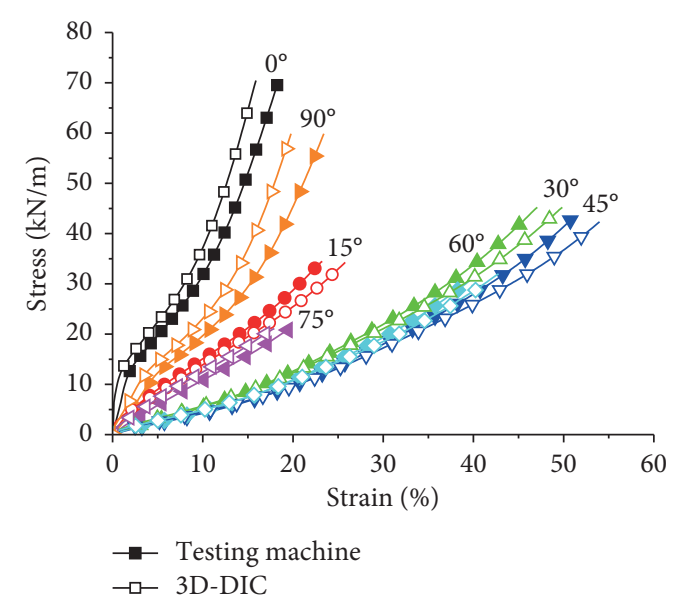

(b)

FIGURE 9: Stress-strain curves from the off-axis tensile tests. (a) Dumbbell shape. (b) Strip shape.

the later stage of tensile loading, the fiber is pulled away from the original position and biased towards the tensile loading direction. As a result, the difference between the strain in the middle area of the specimen and the strain in both clamped ends increases. The nominal strain calculated from the test machine data cannot reflect this difference. The off-axis tensile testing curve of the material has obvious nonlinearity. The curves at small off-axis angles of $0^{\circ}, 15^{\circ}, 75^{\circ}$, and $90^{\circ}$ can be divided into three sections. The first stage is the initial linear section, in which the material is linear elastic. The second stage is the strain strengthening stage, in which the tensile curve begins to change nonlinearly, the strain increases faster, and the stiffness of the material gradually decreases. The third stage is the stress strengthening stage, in which the stress-strain curve becomes linear again. The tensile modulus of the material gradually increases, and the stress-strain curve at large off-axis angles of $30^{\circ}, 45^{\circ}$, and $60^{\circ}$ can be divided into two stages, namely, the initial linear stage and the stress strengthening stage.

The mechanical properties of the coated fabrics are obviously anisotropic, and the tensile strength and elongation at break are greatly affected by the off-axis direction. When tested in the $0^{\circ}$ direction (warp direction), the tensile strength of the coated fabrics is the largest, and the elongation at break is the smallest, followed by $90^{\circ}$. The tensile elongation at break is the largest when tested in the $45^{\circ}$ direction, whereas the tensile strength is reduced to a minimum. The corresponding values at the other off-axis angles are in between these two extremes. The mechanical properties of the coated fabrics are mainly determined by the fibers in the fabric. In the process of weaving the base fabric, the warp fibers are controlled by machine pretension and are nearly completely straight. However, since the weft fibers are interlaced and woven between the warp fibers in accordance with certain rules, the weft fibers are not as straight as the warp fibers (i.e., the weft fibers are bent to a certain degree). During the testing process, the weft fibers are fully straightened first, so the elongation at break at $90^{\circ}$ is greater than that at $0^{\circ}$. The testing results of the specimen above show that the longitudinal and shear strains of the specimen are relatively large under off-axis angles of $30^{\circ}$ and $60^{\circ}$; namely, the coated fabrics are in a tensile-shear coupling state. Under the combined action of normal stress and shear stress, the penetrating fibers in the middle of the specimen are broken, and partially penetrated fibers on both sides are extracted from the matrix. The fibers in the whole cross section are destroyed, which eventually leads to specimen being destroyed. The decrease in fiber utilization weakens the tensile strength of the coated fabrics. When the tensile load is applied in the $45^{\circ}$ direction, the coated fabrics are in the in-plane shear state with maximum shear strain. Under these conditions, the damage to the fiber structure is accelerated, and the utilization of the fibers is minimized, resulting in the minimum tensile strength.

\section{Conclusions}

This paper presents an experimental research on mechanical properties of PVC-coated fabrics by using a noncontact fullfield measurement system in the off-axis tensile test. In the test, the changes of longitudinal and shear strain distributions are analyzed during the entire tensile testing process. The effects of testing results are compared from different specimen shapes and different testing areas, and the main conclusions are as follows:

(1) The longitudinal strain field of the coated fabrics is obviously symmetrically distributed in the off-axis direction. There are certain differences between the two kinds of specimen shapes in the longitudinal strain fields. The longitudinal strain of the dumbbellshaped specimen is evenly concentrated in the middle rectangular area of the specimen. Following the trapezoidal area, the longitudinal strain on both clamped ends is the smallest, whereas there is an area of high strain at the chamfer. The average longitudinal strain in the entire test area is smaller than the longitudinal strain in the center area. As the 
deviation increases from the warp and weft, the data of longitudinal direction calculated by the testing machine is more close to the central area. As to the strip-shaped specimen, the longitudinal strain distributed more uniformly along the tensile loading direction, and the strain near the clamped ends becomes slightly larger. The longitudinal strains of two test areas are basically the same as those calculated by the testing machine.

(2) During the tensile testing process, the shear strain of coated fabrics is gradually increasing. The shear strain field is also distributed symmetrically in the off-axis direction, and the shear strain distribution of the two different shapes of specimens is basically the same. The maximum shear strain occurs at the offaxis angle of $45^{\circ}$ and gradually decreases with deviation. Tensile deformation mainly occurs in the directions of $0^{\circ}$ and $90^{\circ}$, for which the shear strain is basically zero. Deviations from the warp direction result in larger maximum shear strains than deviations from the weft direction.

(3) The off-axis tensile properties of the coated fabrics have obvious anisotropy and nonlinearity, and the progress of the tensile test can be divided into three stages: the initial linear stage, the deformation strengthening stage, and the stress strengthening stage. At $0^{\circ}$, the tensile strength is the largest and the elongation at break is the smallest, which is followed by $90^{\circ}$. At $45^{\circ}$, the elongation at break is the largest and the tensile strength is the smallest. Data of other angles lies in between.

\section{Data Availability}

All data included in this study are available through the corresponding author upon request.

\section{Conflicts of Interest}

The authors declare that they have no conflicts of interest regarding the publication of this paper.

\section{Acknowledgments}

This work was financially supported by the National Natural Science Foundation of China (no. 51678563), Jiangsu Vocational Institute of Architectural Technology (YJA317- 06), the Ministry of Housing and Urban-Rural Development of the People's Republic of China (2017-K1-002), Jiangsu Provincial Department of Housing and Urban-Rural Development (2018ZD247), and Xuzhou Scientific Research Program (KC19013).

\section{References}

[1] B. Bridgens and M. Birchall, "Form and function: the significance of material properties in the design of tensile fabric structures," Engineering Structures, vol. 44, no. 11, pp. 1-12, 2012.
[2] T. D. Dinh, A. Rezaei, L. De Laet, M. Mollaert, D. Van Hemelrijck, and W. Van Paepegem, "A new elastoplastic material model for coated fabric," Engineering Structures, vol. 71, pp. 222-233, 2014.

[3] B. Forster and M. Mollaert, European Design Guide for Tensile Surface Structures, Tensinet, Brussels, Belgium, 2004.

[4] Z. Yingying, Z. Qilin, L. Ke, and K. Bei-lei, "Experimental analysis of tensile behaviors of polytetrafluoroethylene-coated fabrics subjected to monotonous and cyclic loading," Textile Research Journal, vol. 84, no. 3, pp. 231-245, 2014.

[5] Y. Zhang, J. Xu, Y. Cao et al., "Off-axial tensile behaviors and failure mechanisms of PTFE coated fabrics," Journal of Harbin Institute of Technology, vol. 48, no. 12, pp. 135-141, 2016.

[6] L. Zhang, W. Chen, and S. Dong, "Mechanical properties analysis of architectural PVDF/PES fabrics with uni-tensile and bi-axial test," Space Structure, vol. 18, no. 3, pp. 41-48, 2012.

[7] N. Mccormick and J. Lord, "Digital image correlation," Materials Today, vol. 13, no. 12, pp. 52-54, 2010.

[8] J. L. Bartlett, B. P. Croom, J. Burdick, D. Henkel, and X. Li, "Revealing mechanisms of residual stress development in additive manufacturing via digital image correlation," Additive Manufacturing, vol. 22, pp. 1-12, 2018.

[9] T. Rief, J. Hausmann, and N. Motsch, "Development of a new method for residual stress analysis on fiber reinforced plastics with use of digital image correlation," Key Engineering $M a$ terials, vol. 742, p. 6, 2017.

[10] I. Yamaguchi, “A laser-speckle strain gauge," Journal of Physics E: Scientific Instruments, vol. 14, no. 11, pp. 1270-1273, 2000.

[11] W. H. Peters and W. F. Ranson, "Digital imaging techniques in experimental stress analysis," Optical Engineering, vol. 21, no. 3, Article ID 213427, 1982.

[12] A. J. Comer, K. B. Katnam, W. F. Stanley, and T. M. Young, "Characterising the behaviour of composite single lap bonded joints using digital image correlation," International Journal of Adhesion and Adhesives, vol. 40, pp. 215-223, 2013.

[13] Y. Chen, S. Sun, and C. Ji, "Development and application of 3D digital image correlation (3D DIC) in deformation measurement of materials," Journal of Aeronautical Materials, vol. 37, no. 4, pp. 90-100, 2017.

[14] W. Zhang, J. Fan, L. Chen et al., "Application of 2D digital image correlation method in quasi-static tensile experiment," Chinese Journal of Applied Mechanics, vol. 35, no. 5, pp. 138-144, 2018, in Chinese.

[15] Shanghai Construction Engineering Code DG/T J08-20192007, Membrane Structure Inspection Technical Regulations, Shanghai Construction and Management Committee, Shanghai, China, 2007. 